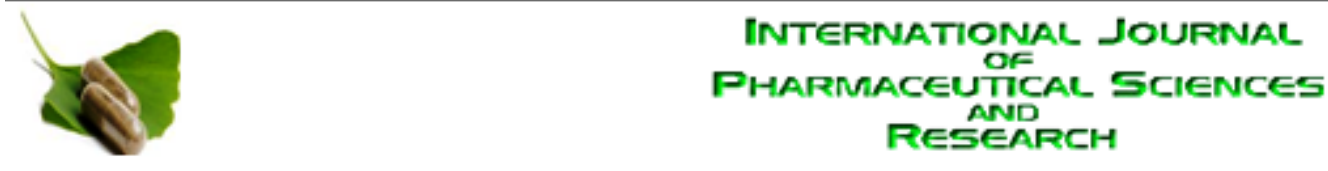

Received on 29 February, 2012; received in revised form 27 June, 2012; accepted 29 June, 2012

\title{
ANTIHYPERTENSIVE MEDICATION PRESCRIBING PATTERNS IN A UNIVERSITY TEACHING HOSPITAL IN SOUTH DELHI
}

Fowad Khurshid ${ }^{* 1,2}$, Mohammed Aqil ${ }^{1}$, Mohammad Shamshir Alam ${ }^{1}$, Prem Kapur ${ }^{3}$ and Krishna K. Pillai ${ }^{1}$

Faculty of Pharmacy ${ }^{1}$, Jamia Hamdard (Hamdard University), New Delhi-110062, India

Pharmacoeconomics and Outcomes Research Unit; Department of Clinical Pharmacy, College of Pharmacy, King Saud University ${ }^{2}$, P.O Box: 2457, Riyadh-11451, Saudi Arabia

Majeedia Hospital ${ }^{3}$, Jamia Hamdard (Hamdard University), New Delhi,-110062, India

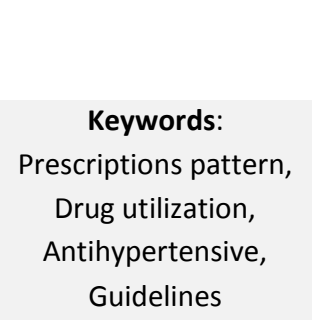

Correspondence to author:

Dr. Fowad Khurshid

Pharmacoeconomics and Outcomes Research Unit; Department of Clinical Pharmacy, College of Pharmacy, King Saud University , P.O Box: 2457, Riyadh11451, Saudi Arabia

\section{ABSTRACT}

Study objective: To investigate the use of antihypertensive drugs in hypertensive patients and to identify whether such pattern of prescription is appropriate in accordance with international guidelines for management of hypertension.

Methods: This was a prospective analysis. A prescription based survey among patients with established hypertension was conducted at the Medicine Out-Patient Department of University Teaching Hospital in South Delhi, India. Data were collected from patients' medical records as well as patients' interviews.

Results: A total of 192 hypertensive patients fulfilled the criteria for inclusion in the study analysis. Combination therapy was used more commonly than monotherapy (54.6\% vs 45.4 ). Among the monotherapy category, the various classes of drugs used were as follows: beta- blockers (28.8\%), diuretics (24.1\%), calcium channel blockers (21.8\%), ACE inhibitors (18.4\%), angiotensin II receptor blockers (5.7\%) and $\alpha 1$ - blocker (1.1\%). With respect to overall utilization pattern, diuretics $(42.2 \%)$ were the most frequently prescribed class, beta- blockers (41.2\%) ranked second followed by calcium channel blockers (39.1\%), ACE inhibitors (26.0\%), angiotensin II receptor blockers (23.4\%) and $\alpha$ 1- blocker (9.4\%). As for individual medicines, amlodipine (35.4\%) was the most commonly prescribed antihypertensive drug followed by atenolol (17.8\%), ramipril (17.2\%) and furosemide (13.0\%). Among the combination therapies, 2- drug treatment was preferred for $75 \%$ of the hypertensive patients with $\mathrm{CCB}$ and $\beta$-blocker being the most frequent drug combination (22.4\%).

Conclusion: The general pattern of antihypertensive utilization seems to be in accordance with the international guidelines for management of hypertension.
INTRODUCTION: Hypertension is associated with increased risk of stroke, myocardial infarction, atrial fibrillation, heart failure, peripheral vascular disease, and renal disease ${ }^{1}$. 
The World Health Report 2002 of the World Health Organization (WHO) states that high blood pressure is the primary or secondary cause of $50 \%$ of all cardiovascular diseases worldwide ${ }^{2}$.

The worldwide burden of hypertension in 2000 was estimated to be 972 million or $26.4 \%$ of the adult world population, with 333 million in economically developed and 639 million in economically developing countries. It has been estimated that by 2025, 1.56 billion individuals will have hypertension; an increase of $60 \%$ from 2000 . Most of this rise can be attributed to an expected increase in the number of people with hypertension in economically developing countries. On the basis of these estimates, almost three-quarter of the world's hypertensive population will be in developing countries ${ }^{3}$.

Hypertension is highly prevalent in India. Data on nationwide survey are unavailable, but there are abundance of region based and local population-based studies on prevalence of hypertension. The Hypertension Study Group, in their multi-centre study in India, found that the overall prevalence of hypertension among elderly individuals was $65 \%{ }^{4}$. In India, the various studies estimated a prevalence rate of hypertension among urban population ranging from $1.24 \%$ in 1949 to $36.4 \%$ in 2003 , and for rural people from $1.99 \%$ in 1958 to $21.2 \%$ in $1994^{5}$.

Bharucha study showed a progressively increasing prevalence with age, with $56.3 \%$ of those $\geq 60$ years and $64.2 \%$ of those $\geq 70$ years having hypertension ${ }^{6}$. Few studies were also carried out comparing different socio economic groups. In the initial study from urban Chennai, Mohan et al., ${ }^{7}$ reported $8.4 \%$ prevalence of hypertension among men and women aged 20 years and above and belonging to the low socio economic group (based on household income, occupation and dietary pattern). Misra et al., ${ }^{8}$ reported $12 \%$ prevalence of hypertension in the slums of Delhi.

A number of national and international guidelines for the treatment of hypertension have been published. The JNC 7 guidelines recommend diuretics as the first line treatment in hypertension 9 . The European guidelines, on the other hand, suggest that unless a special indication exists, any of the five anti hypertensive classes can be used as first line treatment
10. A combination treatment has been recommended as first line intervention, particularly in patient with severe hypertension ${ }^{9}$. A number of drug in various combinations are generally used for effective long term management ${ }^{11}$.

Changes over time in terms of recommended guidelines and innovation in drug formulations have resulted in modification to the prescription patterns of antihypertensive drugs. Therefore, drug utilization studies, which evaluate, and analyze the medical, social, and economic outcomes of the drug therapy are more meaningful, and observe the prescribing attitude of physicians with the aim to provide drug rationally ${ }^{12}$. This kind of medical audit highlights the lacunae in the present prescribing practice of physicians and help in improving the patient health care further ${ }^{13}$.

The present prescription monitoring study for antihypertensive drugs was undertaken in the medicine outpatient department (OPD) of university teaching hospital. The purpose of this study was to investigate the use of antihypertensive drugs in hypertensive patients in order to establish the current trend of pattern of prescribing of antihypertensive drug; and to identify whether such pattern of prescription is appropriate and accordance with international guidelines for pharmacotherapy of hypertension.

METHODS: It was a prospective analysis of medicine utilization patterns in patients with established hypertension. The study protocol was assessed and approved by Jamia Hamdard Institutional Review Board (Approval letter No. JHIRB 07/07, February 15, 2007). The study was carried out in the medicine outpatient department (OPD) of Majeedia hospital, a 150 staffed bed teaching hospital in New Delhi that caters to the health needs of low socioeconomic group population of South Delhi and a campus community consisting of students, faculty, non-teaching and administrative staff and their family members.

The patients included were those who were registered in the medicine OPD during the period February 2007June 2007. An informed consent was taken from patients participating in the study. All hypertensive patients irrespective of age and sex visiting medicine OPD and treated with at least one antihypertensive 
agent were included in the study. Patients who were not treated with antihypertensive drug, mentally retarded and unconscious patients (patients depending on other people for medication administration), drug addicts and patients unable to comply were excluded from the study. The following data were collected: age, sex, registration number, height, weight, waist circumference, hip circumference, diagnosis, duration of illness. Each drug prescribed to the patient was noted as follows: brand/generic name, indication, route of administration, dose, frequency of administration and date of starting the drug.

RESULTS: During the study period, a total of 192 hypertensive patients fulfilled the criteria for inclusion in the study analysis. Demographic characteristics of these 192 patients are presented in Table 1. Of the 192 hypertensive patients 87 (45.4\%) were males and 105 (54.6\%) were females indicating that hypertension is slightly more prevalent in the female gender. The mean age of the patients included in the study was found to be $48.5 \pm 14.5$ years. The age distribution of hypertensive patient was $15(7.8 \%)$ below the age of 30 years, 135 (70.3\%) were between 30 and 60 years and $42(21.8 \%)$ were above 60 years.

TABLE 1: DEMOGRAPHIC CHARACTERISTICS OF HYPERTENSIVE PATIENTS

\begin{tabular}{|c|c|c|c|}
\hline Demographic parameter & All (\%) & Male (\%) & Female (\%) \\
\hline Gender & $192(100)$ & $87(45.4)$ & $105(54.6)$ \\
\hline \multicolumn{4}{|c|}{ Age groups (years) } \\
\hline Under 30 & $15(7.8)$ & $12(13.8)$ & $03(2.8)$ \\
\hline $31-40$ & $48(25.0)$ & $20(23.0)$ & $28(26.6)$ \\
\hline $41-50$ & $49(25.5)$ & $11(12.6)$ & $38(36.2)$ \\
\hline $51-60$ & $38(19.8)$ & $23(26.4)$ & $15(14.3)$ \\
\hline $61-70$ & $25(13.0)$ & $12(13.8)$ & $13(12.4)$ \\
\hline $71-80$ & $15(7.8)$ & $07(8.0)$ & $08(7.6)$ \\
\hline Above 80 & $02(1.0)$ & $02(2.3)$ & --- \\
\hline \multicolumn{4}{|c|}{ Body mass index $\left(\mathrm{kg} / \mathrm{m}^{2}\right)$} \\
\hline$<18.5$ (Under weight) & $13(6.8)$ & $06(6.9)$ & $07(6.7)$ \\
\hline 18.5-22.9 (Normal range) & $60(31.2)$ & $38(43.7)$ & $22(20.9)$ \\
\hline 23-24.9 (Over weight) & $45(23.4)$ & $22(25.3)$ & $23(21.9)$ \\
\hline 25-29.9 (Pre-obese) & $47(24.5)$ & $18(20.7)$ & $29(27.6)$ \\
\hline$>30$ (Obese) & $27(14.1)$ & $03(3.4)$ & $24(22.8)$ \\
\hline \multicolumn{4}{|c|}{ Waist Circumference $(\mathrm{Cm})$} \\
\hline$<90$ & ---- & $69(79.3)$ & ---- \\
\hline$>90$ & ---- & $18(20.7)$ & ---- \\
\hline$<80$ & ---- & ---- & $46(43.8)$ \\
\hline$>80$ & ---- & ---- & $59(56.2)$ \\
\hline \multicolumn{4}{|c|}{ Waist-Hip Ratio } \\
\hline
\end{tabular}

\begin{tabular}{c|c|c|c}
\hline$\leq 0.95$ & ---- & $56(64.4)$ & ---- \\
\hline$>0.95$ & ---- & $31(35.6)$ & --- \\
\hline$\leq 0.85$ & ---- & --- & $19(18.1)$ \\
\hline$>0.85$ & ---- & --- & $86(81.9)$ \\
\hline
\end{tabular}

The maximum number of male hypertensive patients belonged to the age group of 51-60 years whereas female patients were the highest in the age group of 41-50 years. The mean body mass index (BMI) of the study population was $24.10 \pm 4.62 \mathrm{~kg} / \mathrm{m} 2$.

Out of 192 hypertensive patients a total of 74 (38.5\%) had a BMI $>25 \mathrm{~kg} / \mathrm{m} 2,18 \%$ of the male and $59 \%$ of the female patients had a waist circumference higher than the normal limits of $>90 \mathrm{~cm}$ and $>80 \mathrm{~cm}$ respectively whereas $86 \%$ of the female and $31 \%$ of the male patients had a waist-hip ratio higher than the acceptable limits (i.e., $>0.85$ in females and $>0.95$ in males).

A total of 87 (45.3\%) patients received monotherapy. The majority $(n=105)$ of the subjects $(54.7 \%)$ were on the multiple drug therapy. Table $\mathbf{2}$ presents the prescription pattern and rate of antihypertensive drug prescribed for hypertensive patients both as monotherapy and overall utilization profile (mono and combined therapies).

Among the monotherapy category, the various classes of drugs used were as follows $\beta$-blockers (28.8\%), diuretics (24.1\%), calcium channel blockers (21.8\%), ACE inhibitors (18.4\%), angiotensin II receptor blockers (5.7\%) and $\alpha$ 1- blocker (1.1\%).

Amlodipine (21.8 \%) was the most commonly prescribed antihypertensive agent as monotherapy followed by propranolol (17.3\%). However incase of overall utilization pattern of antihypertensive agents, diuretics (42.2\%) were the most frequently prescribed class, $\beta$-blockers (41.2\%) ranked second followed by calcium channel blockers (39.1\%), ACE inhibitors (26.0\%), angiotensin II receptor blockers (23.4\%) and $\alpha$ 1- blocker (9.4\%). Amlodipine (35.4\%) was the most commonly prescribed antihypertensive drug followed by atenolol (17.8\%), ramipril (17.2 \%) and furosemide (13.0\%).

TABLE 2: PATTERNS OF USE OF VARIOUS CLASSES OF ANTIHYPERTENSIVE DRUGS AS MONOTHERAPY AND OVERALL UTILIZATION IN HYPERTENSIVE PATIENTS

Antihypertensive class

Diuretics

$\beta$-Blockers
Overall prescriptions frequency (\%)

$82(42.2)$

$79(41.2)$
Monotherapy prescriptions frequency (\%)

$21(24.1)$

$25(28.8)$ 


\author{
Calcium Channel Blockers \\ ACE Inhibitors \\ Angiotensin II Receptor Blockers \\ $\alpha$ 1- Blocker
}

$75(39.1)$
$50(26.0)$
$45(23.4)$
$18(9.4)$

$19(21.8)$

$16(18.4)$

05 (5.7)

$01(1.1)$
A total of 105 (54.7\%) patients received some combination of antihypertensive agents (Table 3 ). The most prevalent combination of drug was a 2-drug therapy of $\mathrm{CCBs}+\beta$-blockers which was found to be $22.4 \%$ followed by ACEI + Diuretics (7.8\%). Among the three drug combinations, ACEls, $\beta$-blockers and calcium channel blockers comprised the most commonly prescribed combination (Table 4).
TABLE 3: SINGLE ANTIHYPERTENSIVE THERAPY VS. MULTIPLE ANTIHYPERTENSIVE THERAPIES

\begin{tabular}{ccc}
\hline $\begin{array}{c}\text { Drug therapy } \\
\text { prescribed }\end{array}$ & No. of prescriptions & $\begin{array}{c}\% \text { of } \\
\text { prescriptions }\end{array}$ \\
\hline Single drug therapy & 87 & 45.3 \\
\hline \multicolumn{3}{c}{ Multidrug therapy } \\
\hline 2 drug therapy & 79 & 75.2 \\
3 drug therapy & 19 & 18.1 \\
4 drug therapy & 07 & 6.7 \\
Total & 105 & 54.7
\end{tabular}

\section{TABLE 4: PATTERNS OF USE OF ANTIHYPERTENSIVE COMBINATION THERAPY AMONG HYPERTENSIVE PATIENTS}

\begin{tabular}{cccc}
\hline Combination therapy drug regimen & No. of prescriptions & $\begin{array}{c}\text { Percentage (\%) of total } \\
\text { prescription }\end{array}$ & $\begin{array}{c}\text { Percentage (\%) receiving } \\
\text { combination therapy }\end{array}$ \\
\hline Two drug combination & 79 & 41.1 & 75.2 \\
\hline CCBs + $\beta$-Blockers & 43 & 22.4 & 40.9 \\
ACEI+ Diuretics & 15 & 7.8 & 14.3 \\
ACEI + CCBs & 11 & 5.7 & 10.5 \\
ACEI + $\beta$-Blockers & 07 & 3.6 & 6.7 \\
CCBs + Diuretics & 03 & 1.6 & 2.8 \\
\hline Three drug combination & 19 & 9.9 & 18.0 \\
\hline ACEI + $\beta$-Blockers + CCBs & 10 & 5.2 & 9.5 \\
ACEI + $\beta$-Blockers + Diuretics & 07 & 3.6 & 6.6 \\
ACEI + CCBs + Diuretics & 02 & 1.1 & 1.9 \\
\hline
\end{tabular}

CCBs: calcium channel blocker; ACEI: angiotensin converting enzyme inhibitor

Morisky scale was used to predict adherence to prescribed medication therapies. Of the study population, $45.3 \%$ showed a good adherence with the prescribed treatment. Adherence was found to be slightly better in males (24\%) than in females (21.3\%). The Morisky score 4, which indicate a high adherence to pharmacological treatment, was observed in $10.4 \%$ of the patients only.

DISCUSSION: The results of our study suggest that hypertension is more prevalent in female patients (54.6\%) than their male counterparts (45.4\%). The above trend is in conformity to previous Indian study ${ }^{13}$ who reported about $61 \%$ female as against $39 \%$ male hypertensive patients. The number of men (51\%) and women (49\%) was found to be anomalous in another Indian study on hypertensive patients ${ }^{14}$.

In an overseas study conducted in Hong Kong ${ }^{15}$, the prevalence of hypertension was reported as $57 \%$ in females and $43 \%$ in males. A German study ${ }^{16}$ mentions $57 \%$ female vs. $43 \%$ male hypertensive populations. In a contradictory report ${ }^{17}$ out of 1076 patients, $43.9 \%$ females and $56.1 \%$ males, suffered from hypertension in Chandigarh city.

In our study, patients under the age groups of 31-40 years and 41-50 years presented with more complaints of hypertension ( $25 \%$ each) than the other age groups. The above result gives an indication that advanced age is not the only risk factor for hypertension in India. Instead, the above trend can be attributed to the sedentary life style, unhealthy eating habits and increased stress at work. This is an agreement with previous study ${ }^{13}$ reporting $26 \%$ hypertensive patients in 40-49 years age group.

The mean BMI of the patients in our study was approximately $24 \mathrm{~kg} / \mathrm{m} 2$ which implies that the patients are overweight $\left(\mathrm{BMI} \geq 23 \mathrm{~kg} / \mathrm{m}^{2}\right)$ and are on the borderline of becoming obese $\left(B M I \geq 25 \mathrm{~kg} / \mathrm{m}^{2}\right)$, which in itself is a significant risk factor for hypertension. A very high percentage $(38.5 \%)$ of the study patients had $\mathrm{BMI} \geq 25 \mathrm{~kg} / \mathrm{m} 2$ when first reported 
for the study, which is a very common observation in the hypertensive patients. As precedence, mean BMI of hypertensive patients in a study was $28.4 \mathrm{~kg} / \mathrm{m}^{2}$ indicating a tendency towards obesity ${ }^{16}$.

In a survey called "Sentinel Surveillance Systems for CVD in Indian Industrial Population" involving ten centers from different parts of the country, it was concluded that the overall prevalence of overweight/obesity in patients of cardiovascular disorders was $31 \%{ }^{18}$. Another study ${ }^{19}$ carried out among industrial population in Delhi illustrated a prevalence of $35 \%$ in males, with $5 \%$ increase in overweight /obese patients in five years time.

The average number of antihypertensive medicines prescribed per prescription is only 1.8 in our study which is in proximity to 1.9 as reported earlier ${ }^{17}$. There were no generics prescribed during the study period, as the hospital does not have its own formulary and the drugs are being purchased from an in-house retail pharmacy. The prescribing pattern of antihypertensive in our university hospital seems to be in compliance with JNC 7 guidelines.

Diuretics were most frequently prescribed antihypertensive medicines followed by $\beta$-blockers, calcium channel blockers, ACE inhibitors, ARBs and $\alpha$ blockers. The JNC 7 report recommends that in the absence of any specific indications, a diuretic or $\beta$ blocker should be selected as the initial therapy for hypertension ${ }^{9}$. Medicine utilization studies elsewhere have documented major deviations from the guidelines by the prescribers.

For the purpose of sampling, Malhotra et al., 17 reported that $\beta$-blockers were prescribed in $51 \%$ of prescription followed by CCBs (47\%) and ACE inhibitors (46\%) which was very similar to Hong Kong study 15 which documents $51 \% \beta$-blockers, $49 \%$ CCBs, $27 \%$ ACE inhibitors and $24 \%$ diuretics as prescribed antihypertensives. Another report mentions $47 \% \beta$ blockers, 34\% CCBs, 30\% ACE inhibitors and 16\% diuretics ${ }^{14}$.

$\beta$-blockers and CCBs were equally prescribed (68\%) in another study with $6 \%$ prescriptions for ACE inhibitors and only $4 \%$ for diuretics ${ }^{13}$. Two recent studies ${ }^{16,20}$ document ACE inhibitors as the most frequently utilized antihypertensive drug category whereas $\alpha$ - blockers were the least prescribed. CCBs were the most preferred antihypertensive followed by ACE inhibitors, Diuretics and $\beta$-blockers in a study conducted on inpatients in Bangalore, India ${ }^{21}$. A common observation in all the above studies is the under utilization of diuretics which needs intervention by the formulary committees and the health policy makers.

It was observed that $55 \%$ of the patients were prescribed combination therapy (i.e. more than one antihypertensive in the prescription) which is lower than the recommendations ${ }^{22}$ and observations of several other studies which demonstrated that the combination therapy was necessary in at least $70 \%$ of the study population to attain optimal blood pressure control ${ }^{23,24}$. Single drug therapy was recommended for $45 \%$ patients in our hospital. Higher probability of adverse drug reactions due to combination of antihypertensive medicines with concomitant drugs and pharmacoeconomic consideration might be the reasons which can be attributed to lesser inclination of physicians to go for combination therapy in general in our hospital.

For comparison, $73 \%$ of hypertensive patients were prescribed antihypertensive combination in a survey conducted in Nigeria ${ }^{25}$. In another African study conducted in Ghana, $67 \%$ of the hypertensive patients were put on combination therapy and only $33 \%$ received monotherapy ${ }^{26}$. In an Indian study $60 \%$ and $40 \%$ of patients received combination and monotherapy respectively ${ }^{21}$.

Elsewhere, $71 \%$ of hypertensive patients were administered multiple drugs which are consistent with the recommendations (20). More in synchronization with the results of our study, $54 \%$ of the hypertensive patients were prescribed drugs in combination ${ }^{17}$. On the contrary, monotherapy was preferred for $51 \%$ of the patients in a Hong Kong study ${ }^{15}$.

In a major Japanese study conducted on 12,437 hypertensive patients, approximately $62 \%$ of the patients were given monotherapy as against $35 \%$ who received combination treatment and nonpharmacological interventions were recommended for remaining $3 \%$ of the patients ${ }^{27}$. In agreement to above study $58 \%$ of the patients were administered with 
single drug vis-à-vis $42 \%$ hypertensive patients who were put on combination therapy in an Indian study ${ }^{13}$.

The above pattern is further corroborated by another study conducted in India, wherein $59 \%$ of the patient population was prescribed with monotherapy $\left({ }^{14}\right)$.Among the combination therapies 2- drug treatment was preferred for $75 \%$ of the hypertensive patients with $\mathrm{CCB}$ and $\beta$-blocker being the most frequent drug combination. In other studies too, CCB + $\beta$-blocker with $91 \%^{13}, 36 \%^{17}, 32 \%^{15}$, and $9 \%^{14}$ prescriptions was the most preferred drug combination.

A good number of patients (45\%) adhere to the treatment regimen and followed the instructions. Still, more number of patients (55\%) failed to observe the physicians advice and thus were considered poor in compliance. Compliance parameter was much better in our study population than the one reported in an African study with as high as $93 \%$ patients found short on good compliance ${ }^{26}$.

Comprehensive patient counseling in easy language by the healthcare providers might improve the patient's performance on compliance scale.

CONCLUSION: Although this study lacks both breadth and depth, however it provides a reasonable indication of the prescription patterns of antihypertensive agents in a hypertensive population. Our findings suggest that diuretics and $\beta$-blockers were used in large proportion of hypertensive patients and the pattern of antihypertensive therapy was generally consistent with JNC 7 guidelines, those being the current guidelines at the time of our study.

However, there remains potential room for improvement in drug utilization and a critical need for better blood pressure control. Further research is needed to qualify rationale for choice of drug based on demographic data, economic status, concomitant conditions and complications to give additional insight into prescribing patterns of antihypertensive in India.

ACKNOWLEDGEMENT: The authors wish to acknowledge the support and cooperation of all the physicians and patients of Majeedia hospital who participated in the study. The authors thank
Mohammed Alsultan, PharmD, PhD, of King Saud University for reviewing the manuscript.

Conflict of interest: The author declares no conflict of interest.

\section{REFERENCES:}

1. Brown MJ, Haydock S. Pathoaetiology, epidemiology and diagnosis of hypertension. Drugs. 2000; 59 Suppl 2:1-12; discussion 39-40.

2. Guilbert JJ. The world health report 2002 - reducing risks, promoting healthy life. Educ Health (Abingdon). 2003; 16:230.

3. Kearney PM, Whelton M, Reynolds K, Muntner P, Whelton PK, He J. Global burden of hypertension: analysis of worldwide data. Lancet. 2005; 365:217-23.

4. Hypertension Study G. Prevalence, awareness, treatment and control of hypertension among the elderly in Bangladesh and India: a multicentre study. Bull World Health Organ. 2001; 79:490-500.

5. Nissinen A, Bothig $S$, Granroth $H$, Lopez AD. Hypertension in developing countries. World Health Stat Q. 1988; 41:141-54.

6. Bharucha NE, Kuruvilla T. Hypertension in the Parsi community of Bombay: a study on prevalence, awareness and compliance to treatment. BMC Public Health. 2003; 3:1.

7. Mohan J. Prevalence, awareness, treatment, control and risk factors of hypertension in India and its neighborhood: newer data and older perspective. Indian Heart J. 2006; 58:7-9.

8. Misra A, Pandey RM, Devi JR, Sharma R, Vikram NK, Khanna N. High prevalence of diabetes, obesity and dyslipidaemia in urban slum population in northern India. Int J Obes Relat Metab Disord. 2001; 25:1722-9.

9. Chobanian AV, Bakris GL, Black HR, Cushman WC, Green LA, Izzo JL, Jr., et al. Seventh report of the Joint National Committee on Prevention, Detection, Evaluation, and Treatment of High Blood Pressure. Hypertension. 2003; 42:1206-52.

10. European Society of Hypertension-European Society of Cardiology Guidelines C. 2003 European Society of Hypertension-European Society of Cardiology guidelines for the management of arterial hypertension. J Hypertens. 2003; 21:1011-53.

11. Williams B, Poulter NR, Brown MJ, Davis M, Mclnnes GT, Potter $J F$, et al. British Hypertension Society guidelines for hypertension management 2004 (BHS-IV): summary. BMJ. 2004; 328:634-40.

12. Kapoor B RR, Kapoor S. Drug prescribing pattern in a teaching hospital. Ind J pharmacol 1985; 17:168.

13. Tiwari H, Kumar A, Kulkarni SK. Prescription monitoring of antihypertensive drug utilisation at the Panjab University Health Centre in India. Singapore Med J. 2004; 45:117-20.

14. Jhaj R, Goel NK, Gautam CS, Hota D, Sangeeta B, Sood A, et al. Prescribing patterns and cost of antihypertensive drugs in an internal medicine clinic. Indian Heart J. 2001; 53:323-7.

15. Lee PK, Li RK, Chan JC, Chang S, Lee SC, Tomlinson B, et al. A prescription survey in a hospital hypertension outpatient clinic. Br J Clin Pharmacol. 1997; 44:577-82.

16. Pittrow $D$, Kirch $W$, Bramlage $P$, Lehnert $H$, Hofler $M$, Unger $T$, et al. Patterns of antihypertensive drug utilization in primary care. Eur J Clin Pharmacol. 2004;60:135-42.

17. Malhotra S, Karan RS, Pandhi P, Jain S. Pattern of use and pharmacoeconomic impact of antihypertensive drugs in a north Indian referral hospital. Eur J Clin Pharmacol. 2001; 57:535-40. 
18. Reddy KS, Prabhakaran D, Chaturvedi V, Jeemon P, Thankappan KR, Ramakrishnan L, et al. Methods for establishing a surveillance system for cardiovascular diseases in Indian industrial populations. Bull World Health Organ. 2006; 84:4619.

19. Prabhakaran D, Shah P, Chaturvedi V, Ramakrishnan L, Manhapra A, Reddy KS. Cardiovascular risk factor prevalence among men in a large industry of northern India. Natl Med J India. 2005; 18:59-65.

20. Johnson ML, Singh $H$. Patterns of antihypertensive therapy among patients with diabetes. J Gen Intern Med. 2005; 20:8426.

21. Xavier D, Mathew N, Pradeep J, Pais P. Pattern of drug use in hypertension in a tertiary hospital: a cross sectional study in the in-patient wards. Indian Journal of Pharmacology. 2001; 33:456-7.

22. World Health Organization-International Society of Hypertension Guidelines for the Management of Hypertension. Guidelines Subcommittee. J Hypertens. 1999; 17:151-83.
23. Chobanian AV, Bakris GL, Black HR, Cushman WC, Green LA, Izzo JL, Jr., et al. The Seventh Report of the Joint National Committee on Prevention, Detection, Evaluation, and Treatment of High Blood Pressure: the JNC 7 report. JAMA. 2003; 289:2560-72.

24. Chalmers J. The $A B C D$ of anti-hypertensive therapy. J Hypertens. 2002; 20:615-6.

25. Yusuff KB, Balogun $O$. Physicians' prescribing of antihypertensive combinations in a tertiary care setting in southwestern Nigeria. J Pharm Pharm Sci. 2005; 8:235-42.

26. Ohene Buabeng K, Matowe L, Plange-Rhule J. Unaffordable drug prices: the major cause of non-compliance with hypertension medication in Ghana. J Pharm Pharm Sci. 2004; 7:350-2.

27. Mori H, Ukai H, Yamamoto H, Saitou S, Hirao K, Yamauchi M, et al. Current status of antihypertensive prescription and associated blood pressure control in Japan. Hypertens Res. 2006; 29:143-51.

How to cite this article:

Khurshid F, Aqil M, Alam MS, Kapur P and Pilla KKi: Antihypertensive Medication Prescribing Patterns in a University Teaching Hospital In South Delhi. Int J Pharm Sci Res, 2012; Vol. 3(7): 2057-2063. 